\title{
Situational Action Theory and the particular case of settings including a group
}

European Journal of Criminology $1-17$

(C) The Author(s) 2020 Article reuse guidelines: sagepub.com/journals-permissions DOI: I0.1 I77/| 477370820953088 journals.sagepub.com/home/euc

$\Theta$ SAGE

\author{
Julia Kleinewiese $\mathbb{D}$ \\ University of Mannheim, Germany
}

\begin{abstract}
Situational Action Theory (SAT) postulates that personal crime propensity and the setting's criminogenic features are direct causes of crime. This perspective also places a central focus on the moral factors involved. The moral norms of settings have not yet been exhaustively examined in regard to the aspects that may influence them. This theoretical article applies SAT to the particular case of settings including a group. Building upon previous literature on social cohesion in groups (such as team spirit/esprit de corps), the group present in the setting is presumably more likely to be identified by the individual if such group cohesiveness is high. When perceived, the moral norms of the group and deterrence should have an influence through becoming part of the setting in the causation of crime, according to SAT. This application suggests that SAT is a fruitful approach for explaining the impacts of groups on crime.
\end{abstract}

\section{Keywords}

Situational Action Theory, deviance, groups, esprit de corps, particularism

\section{Introduction}

The Situational Action Theory (SAT) is an actor-based theory of crime. As a general theory it is applicable to all kinds of crime. Since its notion refers to individual actions, the question arises: How can SAT explain the corporately committed crimes of group members? The importance of this question can be illustrated by Kammigan et al. (2019), whose application of SAT shows that being a member of a group that condones drugs can increase the likelihood of overreporting drug use (in a survey). Such results in regard to the reporting of deviance (for example, drug use), indicate that behaviour that is deviant according to general norms may be stated, even exaggerated, by members of groups

\section{Corresponding author:}

Julia Kleinewiese, Mannheim Center for European Social Sciences (MZES), University of Mannheim, 68I3।

Mannheim, Germany.

Email: kleinewiese@uni-mannheim.de 
when it corresponds with the group's norms. In SAT, '[t]he moral norms of a setting will vary in the degree to which they correspond with the rules of conduct stated in law' (Wikström et al., 2012: 16). This draws attention to the issue that, in some settings, the moral norms may be more than exclusively general norms. On the basis of this supposition, for settings including a group it might be presumed that group norms play a role. Such group norms could support the general rules and norms (for example, laws) or be conducive to crime.

In SAT, the setting is the individual's immediate environment, including other persons. According to Wikström (for example, 2004) settings can vary in their criminogeneity, that is, in how conducive they are to a specific crime. It is postulated that the moral norms are a central aspect of the criminogenic features of the setting (for example, Wikström and Treiber, 2007). Most empirical studies utilizing SAT assume settings with moral rules that are in accordance with the general rules and norms (for example, laws) of a society (Schulz, 2018) and, therefore, crime prohibitive. There are some exceptions such as those mentioned in Wikström et al. (2012) as well as Cochran (2016). Furthermore, a number of researchers have addressed this aspect and made a call for research on possible crime-conducive moral norms of the setting (see, for example, Jordanoska, 2018; Pauwels, 2018). Despite this, the field of research is not yet exhaustive, especially in regard to theoretical discussions on particular applications. Such a specific application could be, for instance, considering settings with certain social features within the framework of SAT. Hardie's $(2017,2019)$ research, for instance, shows that the (perceived) physical and psychological presence of parents can reduce the likelihood of adolescent misconduct. The social bonds between adolescents and parents can increase the salience of the latter's (typically law-conforming) moral norms in a setting and, therefore, their impact on the adolescents' behaviour (Hardie, 2017, 2019). When there is high social cohesion (for example, in the form of an esprit de corps) in a group, strong social bonds also exist between its members. Therefore, I similarly assume that the perception of one's group in a setting can influence the (perceived) moral norms and deterrence.

In this context, the question arises of how the moral norms of the setting might be constituted (how criminogenic they are) in settings in which several moral rules are present and perceived by the individual. It appears likely that there are both (perceived) general norms as well as particularistic ones in at least some situations. How would the moral rules of the setting be in such an instance? It seems likely that they would be constituted of both universalistic and particularistic norms. In order to elucidate this, it is expedient to apply SAT to a particular setting in which both forms of norms are present and likely to be perceived by the individual. As a first step towards this, a theoretical application will be presented and discussed, using the example of a group directly present in the setting (and of which the individual is a member). In accordance with SAT, the necessary condition for this theoretical approach to be applicable is that the individual must perceive the group in the setting. A theoretical assumption that will be proposed is that the perception of the group in the setting, as well as the strength of the norms' influence, should be higher for groups with strong social (group) cohesion - such as a team spirit or esprit de corps. The current application utilizes previous literature on social cohesion in groups, focusing on esprit de corps (for example, Boyt et al., 2005), as an application in which individuals necessarily perceive themselves as group members and 
feel the influence of the group setting's conditions. From the perspective of this theoretical approach, esprit de corps is expedient - for settings in which groups are present - for looking at the moral rules of the setting. This application of SAT to settings with a group also follows the call for research by Pauwels (2018: 143): 'Future studies should pay attention to other setting characteristics that have relevance, . . . future studies might also want to look at . . . aspects such as the presence of deviant peer groups.'

The ensuing sections proceed as follows. First, an overview of Situational Action Theory will be given. Second, the literature on social cohesion in groups (with a special focus on esprit de corps) as well as empirical results on its positive and negative effects are presented. Third, SAT is applied to the specific case of settings including a group (of which the individual is a member). Finally, the implications and theoretical utility of such an application of SAT are reflected on in the conclusion section.

\section{Situational Action Theory}

SAT is considered to be a general theory of crime because it aims to explain all acts of crime (Wikström, 2006). According to SAT, 'Crime may be defined as an act of breaking a moral rule defined in criminal law' (Wikström, 2006: 63). A focus lies on acts that break laws (Wikström, 2006). However, SAT assumes that laws are merely one specific type of moral rule. The explanatory process for both why people break laws and why they break (other) moral rules is the same. It follows that SAT is also a theory of moral action (Wikström, 2010; Wikström et al., 2012). The specific moral rules that are relevant for a particular action may differ. It is not the type of action but that the action breaks the law that makes it a crime (Wikström, 2010). According to SAT, 'all crimes, in all places, and at all times have in common, the breach of a moral rule (defined in law)' (Wikström, 2010: 216).

This section explicates SAT's central concepts and processes. The theory places a strong emphasis on moral rules, stating that these explicitly prescribe the 'right' and the 'wrong' course of action in a given situation (Wikström et al., 2012). It assumes that moral rules differ from each other in how generally applicable they are across settings (Wikström, 2006). In addition to its focus on the role of moral rules in the explanation of how crimes happen, controls are relevant in SAT. The suggestion is that, when an individual perceives crime as a possible action, they may habitually commit a crime or deliberate on whether or not to commit a crime. The latter occurs when the guiding moral rules in a specific situation are in conflict with one another (Wikström et al., 2012; Wikström and Treiber, 2017).

According to Wikström (for example, 2006), the setting is a subsection of the environment and always refers to what a person is immediately exposed to, because their senses have access to it: 'setting is the part of the environment to which the individual is directly exposed and reacts to (e.g., other persons, objects, and events)' (Wikström, 2004: 18). When individuals take part in settings, they necessarily perceive specific alternatives for acting when exposed to a particular motivator (temptation or provocation). From this viewpoint, the choice that an individual then makes is based on these perceived alternatives (Wikström et al., 2018). It follows that a situation is seen as consisting of the perception of action alternatives as well as the choice process. In accordance with this 
assumption, a situation is generally defined as the result of an interaction between features of the setting and of the person. This interaction between the setting and the person is what presumably leads to the individual perceiving (and choosing) particular action alternatives (for example, Wikström, 2004). Therefore, it is of interest to the theory what combinations of which features of the person and the setting cause particular actions (such as acts of crime) (Wikström et al., 2012; Wikström and Treiber, 2016).

As previously addressed, SAT incorporates the elements 'person' and 'setting' into its conception of situations. These categories lead to two constructs: crime propensity (of the person) and criminogeneity (of the setting). Both of these vary (Wikström, 2014), depending on the exact composition (for example, the perceived motivation, interactions between personal and environmental features) that leads to the situational action.

In SAT, the personal element crime propensity is the predisposition to perceive and then choose to commit an act of crime (as opposed to non-criminal action alternatives) (for example, Wikström, 2004; Wikström et al., 2012; Wikström and Svensson, 2010) - a tendency that appears to be dependent upon how strongly a person's morality and their abilities in respect to self-control facilitate breaking the law (Wikström et al., 2012). Personal morals are defined as 'value-based rules of conduct about what it is right or wrong to do in a particular circumstance' (Wikström and Treiber, 2017: 78). According to Wikström et al. (2012), the morality of a person is dependent on their personal rules of how to act appropriately, as well as on the intensity of their emotions about how important following the corresponding moral rule is. The theory posits that, while personal morality already plays a main part in the perception process, self-control becomes relevant in the choice process but only when there is a conflict between the person's morality and the moral norms of the setting (Wikström, 2014; Wikström and Treiber, 2007). Moreover, self-control is defined as the person's ability (when affected by temptations or provocations) to make the choice to act according to their personal morality (Wikström, 2004). There are two aspects of a person's self-control: (1) their general ability (executive capability) to exercise self-control and (2) the exercising of self-control in a specific situation (Wikström and Treiber, 2007). The former implies more stability whereas the latter could vary owing to situational differences.

The criminogeneity/criminogenic features (of a setting) refer to the degree to which the setting supports acts of crime through facilitating the breaking of law. Settings are termed criminogenic if they have a tendency to encourage acts of crime, and some settings presumably have a higher criminogeneity than others (Wikström, 2004; Wikström et al., 2012). This is constituted by the setting's moral norms and their enforcement, the second of which affects deterrence (Wikström et al., 2012). Furthermore, in the presence of specific motivations, the moral norms of a setting guide how people should conduct themselves (Wikström and Treiber, 2017). Moral contexts differ between settings; that is, the moral norms of the setting and their enforcement, as well as sanctioning, would differ (for example, Wikström, 2004, 2006, 2014; Wikström and Treiber, 2007). Furthermore, settings vary in regard to the extent that their moral norms correspond with the law (Wikström et al., 2012). Deterrence is defined as 'the avoidance of breaking a moral rule (committing an act of crime) because of the fear of consequences' (Wikström, 2008: 347). This is based on the perceived likelihood of interventions (and concomitant possible penalties such as formal punishments and social sanctions) for acts that break the law 
or the specific moral norms of the setting (Wikström, 2004, 2008, 2014), such as perceived surveillance (through, for example, the police, private security personnel or security cameras) and possible punishments. Deterrence plays an active role in an act of crime only when the individual perceives the act as possible and deliberates whether or not to act in such a way (Wikström, 2006). Deterrence may prevent something that would otherwise have taken place (Wikström, 2008).

The situational model, with its interactions, is fundamental to SAT. A person's crime propensity and the setting's degree of criminogeneity are central. It follows that personal morality and self-control interact with the moral norms and deterrence of the setting, leading to an act (of crime): 'When dealing with action the outcome always depends on their interaction' (Wikström, 2004: 9). In SAT, the '[p] erception of action alternatives and the process of choice are the suggested key situational mechanisms that link an individual and his environment (settings) to his actions (inactions)' (Wikström, 2006: 92). This situational perception-choice process shows mechanisms that may lead to an action (crime/no crime) by specific types of individuals in specific types of settings. The situational model hypothesizes that, 'for any particular motivation (temptation or provocation), the resulting action (A) is an outcome of a perception-choice process $(\rightarrow)$ that results from the interaction $(X)$ between relevant personal propensities $(\mathrm{P})$ and exposure to relevant setting inducements (E)' (Wikström and Treiber, 2016: 430). The perceptionchoice model presents a structure of how (1) motivation starts the action process, (2) the moral filter presents alternatives for actions and (3) controls have an effect on the choice process (if there is a conflict between the personal morality and the moral norms of the setting) (Wikström, 2014; Wikström and Treiber, 2016).

SAT also addresses the role of systematic (social) features and people's life stories. It asserts that these factors are not direct causes of crime but may be the causes behind those named in the theory. In this sense, they 'may be regarded as the "causes of the causes"” (Wikström, 2006: 62).

SAT is embedded in the empirical context of the Peterborough Adolescent and Young Adult Development Study (PADS+; see, for example, Wikström et al., 2012). SAT has been tested in numerous empirical studies on specific elements of its models (for example, Hirtenlehner and Hardie, 2016) and some on the overall perception-choice model (for example, Sattler et al., 2018) - for an overview of the studies published between 2006 and 2015, see Pauwels et al. (2018). It has also recently been applied to 'whitecollar crime' (see Craig, 2019; Jordanoska, 2018). A majority of applications have focused on school or university students and, concomitantly, on settings in which they tend to spend time. In such an application of SAT, Cochran (2016) studies elements of academic settings that may be conducive to cheating, and the results indicate that individuals who feel pressured towards deviance by their friends, as well as those who are members of more than the average number of student groups/organizations, are more likely to be involved in academic dishonesty. Similarly, I am suggesting an application of SAT to settings including a group of which the individual is a member, assuming that the group may have an influence on the setting's criminogeneity. This requires first explicating the background of previous research regarding groups that is of relevance for viewing such group influences through the lens of the setting (in SAT). In this context, it seems reasonable to primarily consider social cohesion (such as a team spirit/esprit de 
corps) and its influence on individual group members (for example, pertaining to the group's moral norms).

\section{Esprit de corps}

The previous literature on esprit de corps has two evident opportunities for refinement: some inconsistency pertaining to its definition, as well as (in some instances) the absence of a demarcation between esprit de corps and closely related concepts, such as social cohesion and team spirit (as addressed by Graeff and Kleinewiese, 2020). This section provides an overview of the relevant previous literature, showing that, in spite of the aforementioned limitations, social cohesion in groups (for example, esprit de corps) appears to be a very expedient concept for approaching group processes and effects. One reason for this assumption is that such concepts have been theoretically discussed and empirically examined from diverse viewpoints (in different research fields). Nevertheless, throughout the literature on social cohesion, cohesiveness is considered to be based on the members' attraction to and identification with the group (Boyt et al., 2005). Esprit de corps has been described as a subtype of cohesion (containing a high degree of team spirit) (Koys and DeCotiis, 1991). This perspective exemplifies possible limits within the current literature pertaining to the differentiation between esprit de corps and team spirit. A substantial amount of research applies both concepts interchangeably: some cases present them as directly equivalent (for example, Pahi et al., 2016; Ratzmann et al., 2018) whereas others alternate between them while referring to the same concept (for example, Jaworski and Kohli, 1993; Shoham et al., 2005). As previously indicated in this section, this 'interchangeability' can be seen as a lack in regard to the clear delineation (and, therefore, differentiation) of esprit de corps and team spirit. However, it is also possible to take a more positive stance and evaluate this as an indication that the concepts may be very similar to each other as forms of social cohesion in groups.

The term 'esprit de corps' is historically traceable back to military roots. Rogg (2004) maintains that in the 18th century it was ascribed to nobles (especially those engaged in military work) as a representation of an exclusive upper class. In the late 19th-century German military, it apparently meant having a special nobleness of heart (Elbe, 2004). The Brockhaus encyclopaedia states that it is a 'corps spirit, in corporations, especially the military, the most active participation of each individual towards the common good of all, ... under the setting aside/disregard of all egoistic-personal considerations' (Esprit de Corps, 1911). From the perspective of more recent military literature, social cohesion is commonly divided into subtypes, such as horizontal bonding (direct colleagues) and vertical bonding (superior to subordinates) (Stewart, 1988), or amongst leaders and amongst members of a squad (Mael, 1989).

Fayol (1949) uses esprit de corps to refer to employees' coherence and accord. Esprit de corps has been the focus of both organizational and military literature (see an overview by Boyt et al., 2005). It is assumed that esprit de corps is oriented towards group goals. Jones and James (1979) describe workgroup esprit de corps as a group-level form of social cohesion. Furthermore, it looks probable that the esprit de corps of a group increases when group members face hostile surroundings (Boyt et al., 2005). Esprit de 
corps is generally ascribed a particularistic character: it is exclusively oriented towards the group's members (Blau et al., 1991; Parsons, 1951).

Research on concepts of group cohesion has predominantly placed an emphasis on its positive consequences. Cohesion within groups is commonly associated with positive (work) environments, such as organizational excellence and high adherence to group norms (for example, Boxx et al., 1991; Grant, 2007; Johnson and Johnson, 1991). Identification with the particular group (for example, Tajfel and Turner, 1986) and how attractive a member finds the group (for example, Back, 1951) are believed to be of relevance. Esprit de corps is also prevalently examined in light of its positive effects (in organizational studies, for example, Halpin and Croft, 1962; Jones and James, 1979; Koys and DeCotiis, 1991). Specifically, it is suggested that (a strong) esprit de corps may increase work performance (for example, Flood and Klausner, 2018; Turner, 1933).

Although, overall, most literature on esprit de corps is concerned primarily with its positive outcomes, currently the focus on possible negative effects of esprit de corps is gaining more attention. As supported by the findings of Urien et al. (2017), the related concept group cohesion appears to have a positive effect on job satisfaction. However, the results also indicate that group cohesion seems to increase the negative impact that role ambiguity has on job satisfaction. Furthermore, a strong esprit de corps may reduce people's disposition to question or criticize other in-group members' standpoints (Ratzmann et al., 2018). Moreover, there is some support for the possibility that high social cohesion may be connected to dissociation from people who are not members of the group (Waytz and Epley, 2012), and, in consequence, the likelihood of conflicts between groups might be heightened (Meier and Hinsz, 2004). These studies indicate that strong social cohesion in groups - for instance a high esprit de corps within a workgroup - could have negative effects. Against the backdrop of these findings, it seems that social cohesion in groups can make a contribution in a theoretical approach to the effects of groups in regard to crime.

Literature has also examined esprit de corps' relationship to norms and rules. Take, for instance, an assumption derived by Dungan et al. (2014), which proposes that a person's morality distinguishes between moral norms at the level of the group and generally applicable moral norms. In regard to the current research interest of applying SAT to settings including a group, an example that indicates such a relationship can be that a group's particularistic norms and rules may come into conflict with universalistic norms and rules; the conflicting norms/rules may simultaneously have an effect on the individual (see Graeff, 2012; Pfarrer et al., 2008). In such cases, the individual would presumably have the inclination to adhere to both of the opposing norms (Lüscher, 2013; Merton and Barber, 1963). These competing effects may lead to a trade-off between salient norms (Graeff and Kleinewiese, 2020). A strengthening of esprit de corps could have negative effects because it may intensify the conflicts between group and general norms (see Waytz et al., 2013). Similar to such findings regarding the connection of esprit de corps and group norms, it is feasible that esprit de corps influences the individual's perception of a group (and its moral norms) of which they are a member. Therefore, a stronger esprit de corps could be accompanied by an increase in the influence of the group's particularistic moral norms. Considering these propositions, SAT seems expedient for being applied to the specific case of settings including groups. 


\section{Groups as part of the setting in SAT}

According to Warr (1996), research in the 20th century has led to the group nature of deviant behaviour being well established because offenders tend to commit criminal acts in groups. Furthermore, 'when a situation primes a sense of in-group cohesion or outgroup antipathy, this also may lower thresholds for the collective crime under consideration' (McGloin and Rowan, 2015: 491). From the SAT perspective, groups that are part of the setting could be considered in their influence on the likelihood of a criminal act being committed in such specific situations.

In SAT, the individual is connected with the environment by what they actually perceive of it (Wikström, 2004, 2006; Wikström et al., 2018). Therefore, within this theoretical framework, it appears reasonable that the esprit de corps of a group that is present in the setting (and of which the individual is a member) would increase the perception of the group and its moral norms (as well as deterrence). From this perspective, the current section proposes that - in SAT for the case of settings including groups - the moral norms of the group may contribute to the moral norms of the setting. Following this line of argumentation, the setting including a group would have moral norms that could be influenced by both the group norms and the general norms and rules (for example, laws). Additionally, deterrence of the setting might be constituted by both the group deterrence and general deterrence. Therefore, I suggest that, in this specific type of setting, the group (norms and deterrence) could influence the moral context (of the setting).

It seems feasible that strong group morality may influence individual members in relation to acts of crime, as similarly indicated by Dungan et al. (2014: 109) for the case of corruption: 'group-based morals may also encourage individuals to condone corrupt behaviour.' Moreover, Pinto et al. (2008) reason that the relationship between the individual (level) and the group (level) appears to be important for explaining corruption. Closely linked to these suggestions, I propose that examining possible impacts of groups in a setting where they are present is relevant for explaining particular acts of deviance in specific situations. The previous overviews of SAT and the concept of esprit de corps have laid a foundation for this step. This theoretical perspective aims to apply SAT to the specific case of crime in group settings, with a focus on the possible connection of esprit de corps and group norms with the moral norms of the setting. Because groups may be conceived of as a part of the immediate environment (the setting), the assumption is proposed that groups can have an influence in the causation of crime, from the perspective of SAT.

Coleman (1990) posits that norms do not occur when the socially determined right to act in a given manner lies with the person; instead, he asserts that norms require this right to be held by other people. It seems reasonable to suggest that norms enforce the external accountability (by others) of an individual regarding adherence to their principles (see Brennan et al., 2013). Presumably, norms can be highly relevant for explaining criminal acts because, considering crime to be a subtype of acts of deviance, general norms must exist for the individual to deviate from them. For instances of corruption, Graeff (2005) states that corrupt acts can be controlled by norms of corruption, which explicitly define how the individual should proceed. SAT describes moral norms as mutually held rules regarding action (Wikström and Treiber, 2017). For particular settings, they specify what 
the right or wrong course of action is; furthermore, '[t]hey are prescriptions held by others for what are acceptable reactions and responses to specific motivators' (Wikström, 2019: 270). Therefore, from this perspective, the 'moral' components of the person and the setting are defined by SAT's emphasis on rules regarding what right and wrong action is. Whereas social norms can (depending on the viewpoint) be attitudes that some literature links to behaviour (see Bicchieri et al., 2018), the moral elements of SAT clearly focus on the action.

For the specific case of settings including a group, it seems reasonable to consider the central propositions of SAT, as presented in the section 'Situational Action Theory' above. These posit the setting (its criminogeneity) and the person (their crime propensity) to be the direct causes of crime, assuming that the criminogeneity of a setting would consist of moral norms and deterrence, while the crime propensity of a person would consist of personal morality and self-control (see, for example, Wikström, 2014). In the suggested perception-choice process, ${ }^{1}$ a (perceived) motivation - temptation or provocation - initiates the process. The moral aspects then interact in the 'moral filter' and the control aspects might interact in the 'controls' (Wikström, 2014; Wikström et al., 2012; Wikström and Treiber, 2017). To illustrate these propositions for the case of settings including a group of which the individual is a member, the following hypothetical scenario is described and explicated: a moral norm of a group of adolescents with a strong esprit de corps could be that stealing is a good way of getting money. Whenever the group is present in the setting and perceived by the individual (a member of the group), this moral group norm, as well as the general rules and norms, would constitute the moral norms of the setting. In such circumstances, when the individual is confronted with a motivation, these moral norms of the setting would interact with the personal morality of the individual in the moral filter and would influence whether or not the individual perceived an act of crime as an option. If not, this would lead to a 'no crime' action. If they do perceive crime as an option, this would either habitually lead to a criminal act or to a deliberation in which the controls (self-control and deterrence, the latter constituted of both general deterrence and the group deterrence) would come into play and lead to either a 'crime' or a 'no crime' action, such as stealing from a stranger in a public space. The influence of the group norms would be in opposition to the general norms (in the form of laws) and could be in accordance or in conflict with an individual's personal morality.

This article places an emphasis on the moral elements of SAT because the theory proposes them to be of primary importance (see, for example, Wikström, 2006). Nevertheless, it assumes that the control elements may also play a role in the causation of crime: 'Controls influence the process of choice when there is conflicting rule-guidance (regarding perceived action alternatives)' (Wikström et al., 2012: 23). In the currently proposed application of SAT, this premise would also apply for deterrence of settings that contain generally applicable norms as well as group norms. This might include presence and/or surveillance as well as possible sanctions both in regard to the general norms and rules (through, for example, policemen) and the group norms (through members of the group). Likewise, Wikström (2015) states that deterrence may also enforce criminogenic norms (in addition to non-criminogenic norms). Therefore, it might be suggested that the aforementioned would be conceivable both for settings in which the group norms conform to the general norms and for settings in which they differ. Consider, 
for instance, the following scenario, which exemplifies the aforementioned propositions: a policeman sees that a fellow group member has used excessive violence (beyond what would be justifiable according to general rules). His personal morality prescribes that it is right to report colleagues' misconduct during work assignments. His workgroup has a strong esprit de corps and moral norms that prescribe not reporting the excessive use of violence by a fellow group member to a supervisor (conflicting rule guidance). In deliberation, he may be affected by his self-control and the group deterrence (for example, are other members present?) as well as the general deterrence (for example, external special investigators that are present) as the 'deterrence of the setting'.

A theoretical surplus could be seen in the current approach's connection to previous literature on the universalism-particularism differentiation (see, for example, Blau, 1962; Blau et al., 1991; De Blasio et al., 2019). It seems reasonable to suggest that this perspective is relevant for the presumed importance of moral norms in regard to actions as well as the (as shown in the section 'Esprit de corps') suggested influences of social group cohesion (for example, in the form of an esprit de corps) on individual members. These can be considered in the framework of the differentiation between universalism and particularism in which the former is assumed to refer to common judgements shared by all individuals of a given society, independent of their personal conditions, and the latter is posited to indicate those judgements based on individuals' personal circumstances (Blau, 1962). This perspective also foregrounds a presumed relevance of such judgements (both universalistic and particularistic) to actions. Blau (1962: 166) generally posits that ' $[\mathrm{u}]$ niversalistic standards produce social differentiation' whereas '[p] articularistic standards typically produce segregating boundaries in the social structure'. This position expresses the particularism of (in-)group standards, which can be explicated, for instance, by standards as prejudices: 'A prejudice shared by all, even the minority in question, reflects a universal standard; only a bias confined to the ingroup reflects a particularistic one' (Blau, 1962: 165). Furthermore, one might even suggest that the differentiation between the in-group and the out-group is central to the definition of particularism: 'particularism refers to the fact that people's orientations toward the ingroup differ from those toward the outgroup' (Blau, 1962: 164). It follows that, from this theoretical perspective, the universalism-particularism differentiation is that features (for example, esprit de corps, norms) referring to the group and its members are considered to be particularistic whereas features that refer to all individuals of the general society (for example, general rules and norms) would be categorized as universalistic. In the current framework of applying SAT to the specific circumstance of settings including a group, this could imply that both universalistic moral norms and deterrence as well as the group's particularistic moral norms and deterrence may contribute to the influences of the setting on action. It is proposed that the group norms may prescribe what 'right' or 'wrong' action is in a given situation, according to the group. This should not be taken to indicate that the group's norms are postulated to be contrary to general norms and rules (for example, laws); however, they might be. Based on the literature pertaining to particularism and universalism (Blau, 1962), it looks probable that the general norms and rules could not be particularistic because they are potentially aimed at all members of the entire society. The (general) moral rules are assumed to include formalized rules (for example, laws) but also informal social norms (for example, not smoking 
near children; not pushing or skipping ahead in a queue) (see Ehrlich and Ziegert, 2017). In the sense of these suggestions, it seems probable that, when the general norms and rules are highly effective, the moral norms of the setting should closely correspond with them. It is probable that at least some influence on the setting's moral norms would be present in the form of laws. The moral norms of the setting (when groups are present and perceived) might be influenced by both the general norms and the group norms, showing that in such circumstances groups may play a role in the causation of crime. In regard to the presumed influence of groups on acts (of crime) conducted by individual members, SAT is a theory of crime causation that has been shown to be suitable for a (theoretical) explanation.

\section{Conclusions and future research}

As the theoretical application pertaining to group crime shows, the actor-based approach of SAT can be utilized by including group influences in the framework of one of its two direct causes of crime: the setting. Furthermore, as part of the setting, groups could influence the perception-choice process, which accounts for the possible steps that result in an action (either a crime or not a crime). The setting including a group presents a specific case of settings in which the moral rules may be affected by both universalistic and particularistic norms. Therefore, it is a very specific case that, nevertheless, may illustrate a more general reason why settings can vary in their criminogeneity. Consider, for example, such propositions in regard to corruption: for some situations that could lead to an act of corruption there may be a criminogenic setting, influenced by particularistic moral norms that would be highly salient and, hence, increase the criminogenic features of the setting - even though the universalistic norms and rules (for example, laws) would also be present. Such particularistic moral norms might be those of a group with strong social cohesion, even an esprit de corps. As put by an expert on corruption: 'It is a sense of community, a feeling of togetherness, a confirmed fellowship, the pursuit of a common goal, . . . so that there is a communal spirit, because these actions allow a better financial endowment for everyone' (Campbell and Göritz, 2014: 304).

To illustrate the expedience of the current endeavour, consider the following two scenario variations, focusing on the moral components: an individual happens upon a situation in which it would be possible to perceive stealing a purse that is not being closely watched by its owner (temptation). In the first variation of the scenario, the setting's (perceived) moral norms would comply with the general laws, dictating that stealing is illegal ('wrong'). If the individual's personal moral norms were to dictate that stealing is a 'wrong' action, then they would not be likely to act as a thief (no crime) in this situation by taking the purse. However, consider a second variation of this scenario in which the individual is the member of a gang (group) with moral norms that dictate that stealing is a 'right' action. Keeping all other features of the scenario the same as before, if the individual were to perceive the gang (group) because of other gang members present in the setting, this should increase the (perceived) criminogeneity of the setting and, so, the likelihood that the individual would choose to steal the purse (crime).

The importance of considering factors such as groups regarding the criminogeneity of settings becomes clear when reflecting upon the question of why individuals with a high 
personal morality in settings with high general moral norms might still commit criminal acts, or, conversely, why individuals with a low personal morality in settings with low salience of the general moral norms sometimes do not commit a criminal act (when confronted with temptations or provocations). This is in line with the empirical findings of Wikström et al. (2012: 408): 'even if crime prone young people committed most of their offences in criminogenic settings. . ., they did not offend during most of the time they spent in such settings. There are apparently also other important factors that affect settings' criminogeneity and the extent to which they trigger acts of crime. For example, we have not yet measured social-psychological factors, such as those that relate to social relationships and group dynamics.'

My theoretical approach to explaining the group factor in crime in such specific settings by applying SAT also aims at stimulating a theoretical debate on the integration of different aspects of the setting for the constitution of its moral norms (and deterrence). This may go beyond the current focus on groups and could be examined in regard to other elements that are highly relevant in specific situations. It is also mutually complementary to theoretical and empirical research on SAT such as Hardie's (2017) discussion of differing moral rules in settings as a result of individuals that are present (for example, parents and peers) and possible influences on the likelihood of a criminal act.

This approach further aims at presenting the theoretical elements and interrelations in such a form that easily allows them to be linked with an empirical research design. The specificity of the presented perspective implies that it would be useful for application and testing in empirical endeavours. In such studies, it would be possible to test the typical relevant situations, but also to explore the limits of the applicability of an element such as group features as part of the setting. Similarly, Kroneberg and Schulz (2018) state that it would be expedient to extensively measure the moral norms and rules of settings, and they suggest that varying them experimentally would be the best option. They argue that knowing the places where time is spent and even the number of peers present, of crime prone individuals, might not deliver a sufficient amount of information on the norms and rules of the settings. Furthermore, they posit that these moral rules strongly depend on the moral norms held by the peers present. They call for future research on this topic. Conducting a study that takes the moral norms of the present group into account as part of the setting could be the next expedient step. Testing the theoretical assumptions in this article for members of groups with a strong esprit de corps (such as the military or the police) would be particularly interesting. This may possibly lead to results predominantly supporting the current theoretical propositions or it may imply that some changes are necessary (or perhaps even that some of the postulated aspects are irrelevant). This would not only broaden our understanding of how groups have an effect in the causation of criminal acts but also encourage the debate on other setting elements and the situations in which they may be perceived. For instance, another step that might be taken in examining the role of particularistic moral norms within settings in SAT could be investigating organizational cultures, for example in regard to explaining police deviance or sexual harassment in the workplace (see Jordanoska, 2018, for a specific call for research).

This application of SAT to groups is also theoretically fruitful in a more general sense: it shows how universalistic and particularistic features might be viewed as an important factor within the moral norms - in the framework of SAT - and, therefore, how they may 
simultaneously influence individuals' likelihood of committing a criminal act. This perspective draws on previous literature, assuming the postulated differentiation by Blau (1962) and Blau et al. (1991), foregrounding the issue that a particular action may be influenced by several features that are all universalistic or all particularistic. In the current approach, this perspective is illustrated by the particularistic nature of both the esprit de corps and the group's norms. Furthermore, the application of SAT to group settings also proposes theoretical reasons supporting that both universalism and particularism may affect an actor, for instance when both are present in a setting. This latter argument pertains to the issue that both (universalistic) general moral norms in the setting and (particularistic) moral group norms may influence the overall moral norms of such a specific setting. This furthers a point posited by Blau (1962: 163): 'An orientation is typically influenced by a number of factors, some of which may act as universalistic and others as particularistic standards.' Such combined effects on action could be conceivable when the universalistic and particularistic features differ, as well as when they are in accordance with each other in regard to the action they indicate. In this sense, the current approach and the particularism-universalism differentiation indicate a specific theoretical application of the perception-choice process in which differing processes may lead to crime/no crime outcomes (see, for example, Wikström, 2014). Furthermore, the approach taken here adds a further angle to literature that suggests that particularism and group solidarity are closely linked (for example, Parsons et al., 1953) by showing how the related concept of esprit de corps may be closely connected with particularism. Through the perspective of a SAT application, this indicates that a group's particularistic features, such as its moral norms and its esprit de corps, may be brought into connection in theory on deviance. Blau (1962: 166) posits that '[p]articularism is, indeed, both an expression and a condition of the solidarity of the subgroup . . . but for this very reason it creates some segregating barriers in the larger collectivity'. Following this proposition, the current approach of applying SAT to settings including groups theoretically suggests that their social cohesion (for example, an esprit de corps) and other particularistic features may sometimes have negative effects in regard to the general society and its norms and rules.

This article shows that SAT is able to theoretically explain the (corporately) committed crimes of group members when it is applied to the particular case of settings including a group, even taking social cohesion into account. This is an approach that could be expedient for application in empirical research that is interested in group effects in the causation of crime.

\section{Funding}

The author(s) received no financial support for the research, authorship, and/or publication of this article.

\section{ORCID iD}

Julia Kleinewiese (iD https://orcid.org/0000-0003-0053-219X 


\section{Note}

1. For details on the perception-choice process in SAT, see, for example, Wikström (2014).

\section{References}

Back KW (1951) Influence through social communication. The Journal of Abnormal and Social Psychology 46(1): 9-23.

Bicchieri C, Muldoon R and Sontuoso A (2018) Social norms. In: Zalta EN (ed.) The Stanford Encyclopedia of Philosophy (Winter 2018 Edition). URL (accessed 12 August 2020) : https:// plato.stanford.edu/entries/social-norms/.

Blau PM (1962) Operationalizing a conceptual scheme: The universalism-particularism pattern variable. American Sociological Review 27(2): 159-169.

Blau PM, Ruan D and Ardelt M (1991) Interpersonal choice and networks in China. Social Forces 69(4): 1037-1062.

Boxx WR, Odom RY and Dunn MG (1991) Organizational values and value congruency and their impact on satisfaction, commitment, and cohesion: An empirical examination within the public sector. Public Personnel Management 20(1): 195-205.

Boyt T, Lusch R and Mejza M (2005) Theoretical models of the antecedents and consequences of organizational, workgroup, and professional esprit de corps. European Management Journal 23(6): 682-701.

Brennan G, Eriksson L, Goodin RE et al. (2013) Explaining Norms. New York: Oxford University Press.

Campbell J-L and Göritz AS (2014) Culture corrupts! A qualitative study of organizational culture in corrupt organizations. Journal of Business Ethics 120(3): 291-311.

Cochran JK (2016) Moral propensity, setting, and choice: A partial test of Situational Action Theory. Deviant Behavior 37(7): 811-823.

Coleman JS (1990) Foundations of Social Theory. Cambridge, MA: Harvard University Press.

Craig JM (2019) Extending Situational Action Theory to white-collar crime. Deviant Behavior 40(2): 171-186.

De Blasio G, Scalise D and Sestito P (2019) Universalism vs. particularism: A round trip from sociology to economics. Review of Social Economy. DOI: 10.1080/00346764.2019.1663908.

Dungan J, Waytz A and Young L (2014) Corruption in the context of moral trade-offs. Journal of Interdisciplinary Economics 26(1-2): 97-118.

Ehrlich E and Ziegert KA (2017) Fundamental Principles of the Sociology of Law. New York: Routledge.

Elbe M (2004) Der Offizier: Ethos, Habitus, Berufsverständnis. In: Gareis SB and Klein P (eds) Handbuch Militär und Sozialwissenschaft. Wiesbaden: VS Verlag für Sozialwissenschaften, $418-431$.

Esprit de Corps (1911) In: Brockhaus' Kleines Konversations-Lexikon Bd. 1. Leipzig: F. A. Brockhaus.

Fayol H (1949) General and Industrial Management. Translated by Storrs C. London: Sir Isaac Pitman \& Sons.

Flood F and Klausner M (2018) High-performance work teams and organizations. In: Farazmand A (ed.) Global Encyclopedia of Public Administration, Public Policy, and Governance. Cham: Springer.

Graeff P (2005) Why should one trust in corruption? The linkage between corruption, norms and social capital. In: Lambsdorff JG, Taube M and Schramm M (eds) The New Institutional Economics of Corruption. New York: Routledge, 40-58. 
Graeff P (2012) Ambiguitätstoleranz und Anfälligkeit für Korruption in der Organisationsberatung. In: Haubl R, Möller H and Schiersmann C (eds) Positionen. Beiträge zur Beratung in der Arbeitswelt. Calden: Kassel University Press, 1-8.

Graeff P and Kleinewiese J (2020) Esprit de corps as a source of deviant behavior in organizations: Applying an old concept with a new livery. In: Pohlmann M, Dannecker G and Valarini E (eds) Bribery, Fraud, Cheating: How to Explain and to Avoid Organizational Wrongdoing? Wiesbaden: Springer, 219-245.

Grant AM (2007) Relational job design and the motivation to make a prosocial difference. Academy of Management Review 32(2): 393-417.

Halpin AW and Croft DB (1962) The Organizational Climate of Schools. Chicago: Midwest Administration Center, University of Chicago.

Hardie B (2017) Why monitoring doesn't always matter: The situational role of parental monitoring in adolescent crime. Doctoral thesis, University of Cambridge. DOI: https://doi. org/10.17863/CAM.15484.

Hardie B (2019) Why monitoring doesn't always matter: The interaction of personal propensity with physical and psychological parental presence in a situational explanation of adolescent offending. Deviant Behavior. DOI: 10.1080/01639625.2019.1673924.

Hirtenlehner H and Hardie B (2016) On the conditional relevance of controls: An application of Situational Action Theory to shoplifting. Deviant Behavior 37(3): 315-331.

Jaworski BJ and Kohli AK (1993) Market orientation: Antecedents and consequences. Journal of Marketing 57(3): 53-70.

Johnson DW and Johnson FP (1991) Joining Together: Group Theory and Group Skills. Englewood Cliffs, NJ: Prentice-Hall.

Jones AP and James LR (1979) Psychological climate: Dimensions and relationships of individual and aggregated work environment perceptions. Organizational Behavior and Human Performance 23(2): 201-250.

Jordanoska A (2018) The social ecology of white-collar crime: Applying situational action theory to white-collar offending. Deviant Behavior 39(11): 1427-1449.

Kammigan I, Enzmann D and Pauwels LJR (2019) Over- and underreporting of drug use: A crossnational inquiry of social desirability through the lens of Situational Action Theory. European Journal on Criminal Policy and Research 25(3): 273-296.

Koys DJ and DeCotiis TA (1991) Inductive measures of psychological climate. Human Relations 44(3): 265-285.

Kroneberg C and Schulz S (2018) Revisiting the role of self-control in Situational Action Theory. European Journal of Criminology 15(1): 56-76.

Lüscher K (2013) Das Ambivalente Erkunden. Familiendynamik 38(3): 238-247.

Mael FA (1989) Measuring Leadership, Motivation, and Cohesion among U.S. Army Soldiers. Technical Report 867. Alexandria, VA: U.S. Army Research Institute for the Behavioral and Social Sciences.

McGloin JM and Rowan ZR (2015) A threshold model of collective crime. Criminology 53(3): 484-512.

Meier BP and Hinsz VB (2004) A comparison of human aggression committed by groups and individuals: An interindividual-intergroup discontinuity. Journal of Experimental Social Psychology 40(4): 551-559.

Merton RK and Barber E (1963) Sociological ambivalence. In: Tiryakian EA (ed.) Sociological Theory, Values, and Sociocultural Change: Essays in Honor of Pitirim A. Sorokin. New York: Free Press, 91-120. 
Pahi MH, Shah SMM, Ahmed U et al. (2016) Investigating the issue of nurse job satisfaction: Role of esprit de corps, task significance, self-efficacy and resilience: A case study. International Journal of Academic Research in Business and Social Sciences 6(4): 339-355.

Parsons T (1951) The Social System. England: Routledge \& Kegan Paul.

Parsons T, Bales RF and Shils EA (1953) Working Papers in the Theory of Action. Glencoe, Ill: The Free Press.

Pauwels LJR (2018) Analysing the perception-choice process in Situational Action Theory: A randomized scenario study. European Journal of Criminology 15(1): 130-147.

Pauwels LJR, Svensson R and Hirtenlehner H (2018) Testing Situational Action Theory: A narrative review of studies published between 2006 and 2015. European Journal of Criminology 15(1): 32-55.

Pfarrer MD, Decelles KA, Smith KG et al. (2008) After the fall: Reintegrating the corrupt organization. Academy of Management Review 33(3): 730-749.

Pinto J, Leana CR and Pil FK (2008) Corrupt organizations or organizations of corrupt individuals? Two types of organization-level corruption. Academy of Management Review 33(3): 685-709.

Ratzmann M, Pesch R, Bouncken R et al. (2018) The price of team spirit for sensemaking through task discourse in innovation teams. Group Decision and Negotiation 27(3): 321-341.

Rogg M (2004) Der Soldatenberuf in Historischer Perspektive. In: Gareis SB and Klein P (eds) Handbuch Militär und Sozialwissenschaft. Wiesbaden: VS Verlag für Sozialwissenschaften, 396-408.

Sattler S, Graeff P, Sauer C et al. (2018) Der illegale Verkauf verschreibungspflichtiger Medikamente zur kognitiven Leistungssteigerung: Eine vignetten-basierte Studie rationaler und normativer Erklärungsgründe. Monatsschrift für Kriminologie und Strafrechtsreform 101(3-4): 352-379.

Schulz S (2018) Selbstkontrolle und Kriminelle Neigung in der Modernen Kriminologischen Theoriediskussion. In: Hermann D and Pöge A (eds) Kriminalsoziologie: Handbuch für Wissenschaft und Praxis. Baden-Baden: Nomos, 91-106.

Shoham A, Rose GM and Kropp F (2005) Market orientation and performance: A meta-analysis. Marketing Intelligence \& Planning 23(5): 435-454.

Stewart NK (1988) South Atlantic Conflict of 1982: A Case Study in Military Cohesion. Research Report 1469. Alexandria, VA: U.S. Army Research Institute for the Behavioral and Social Sciences.

Tajfel H and Turner JC (1986) The social identity theory of intergroup behavior. In:Worchel S and Austin WG (eds) Psychology of Intergroup Relations. Chicago: Nelson-Hall, 7-24.

Turner CE (1933) Test room studies in employee effectiveness. American Journal of Public Health and the Nation's Health 23(6): 577-584.

Urien B, Osca A and García-Salmones L (2017) Role ambiguity, group cohesion and job satisfaction: A demands-resources model (JD-R) study from Mexico and Spain. Revista Latinoamericana de Psicología 49(2): 137-145.

Warr M (1996) Organization and instigation in delinquent groups. Criminology 34(1): 11-37.

Waytz A and Epley N (2012) Social connection enables dehumanization. Journal of Experimental Social Psychology 48(1): 70-76.

Waytz A, Dungan J and Young L (2013) The whistleblower's dilemma and the fairness-loyalty tradeoff. Journal of Experimental Social Psychology 49(6): 1027-1033.

Wikström P-OH (2004) Crime as alternative: Towards a cross-level Situational Action Theory of crime causation. In: McCord J (ed.) Beyond Empiricism: Institutions and Intentions in the Study of Crime. New Brunswick, NJ: Transaction Publishers, 1-37. 
Wikström P-OH (2006) Individuals, settings, and acts of crime: Situational mechanisms and the explanation of crime. In: Wikström P-OH and Sampson RJ (eds) The Explanation of Crime: Context, Mechanisms and Development. Cambridge: Cambridge University Press, 61-107.

Wikström P-OH (2008) Deterrence and deterrence experiences: Preventing crime through the threat of punishment. In: Shoham S, Beck O and Kett M (eds) International Handbook of Penology and Criminal Justice. Boca Raton, FL: CRC Press, 345-378.

Wikström P-OH (2010) Explaining crime as moral actions. In: Hitlin S and Vaisey S (eds) Handbook of the Sociology of Morality. New York: Springer Verlag, 211-239.

Wikström P-OH (2014) Why crime happens: A Situational Action Theory. In: Manzo G (ed.) Analytical Sociology: Actions and Networks. Chichester: John Wiley \& Sons, 74-94.

Wikström P-OH (2015) Situational Action Theory. Monatsschrift für Kriminologie und Strafrechtsreform 98(3): 177-186.

Wikström P-OH (2019) Situational Action Theory: A general, dynamic and mechanism-based theory of crime and its causes. In: Krohn MD, Hendrix N, Hall GP and Lizotte AJ (eds) Handbook on Crime and Deviance. Cham: Springer, 259-281.

Wikström P-OH and Svensson R (2010) When does self-control matter? The interaction between morality and self-control in crime causation. European Journal of Criminology 7(5): 395410.

Wikström P-OH and Treiber K (2007) The role of self-control in crime causation: Beyond Gottfredson and Hirschi's General Theory of Crime. European Journal of Criminology 4(2): 237-264.

Wikström P-OH and Treiber K (2016) Situational theory: The importance of interactions and action mechanisms in the explanation of crime. In: Piquero AR (ed.) The Handbook of Criminological Theory. Chichester: John Wiley \& Sons, 415-444.

Wikström P-OH and Treiber K (2017) Beyond risk factors: An analytical approach to crime prevention. In: Teasdale B and Bradley MS (eds) Preventing Crime and Violence. Cham: Springer, 73-87.

Wikström P-OH, Mann RP and Hardie B (2018) Young people's differential vulnerability to criminogenic exposure: Bridging the gap between people- and place-oriented approaches in the study of crime causation. European Journal of Criminology 15(1): 10-31.

Wikström P-OH, Oberwittler D, Treiber K and Hardie B (2012) Breaking Rules: The Social and Situational Dynamics of Young People's Urban Crime. Oxford: Oxford University Press. 